\title{
RIGHT VENTRICULAR OUTFLOW RECONSTRUCTION WITH NONSUTURED PEDICLED AUTOLOGOUS PERICARDIUM
}

Koichi Tabayashi, MD, Yoshiaki Tanaka, MD, Masato Endo, MD, Sadahiro Sai, MD, Shinya Masuda, MD, and

Mitsuaki Sadahiro, MD, Sendai, Japan

Occasionally, patients with pulmonary atresia with ventricular septal defect, transposition of the great arteries with pulmonary stenosis, double-outlet right ventricle associated with pulmonary stenosis, or truncus arteriosus require right ventricular (RV) outflow tract reconstruction with a tubular graft. Homograft, heterograft, or valved pericardial conduits have been used mainly. However, many patients who undergo such reconstruction later require reoperation because of stenosis or obstruction caused by shrinkage, calcification, and intimal hyperplasia. The reoperation rate has been reported to be $8 \%$ to $69 \%$ at 5 to 15 years after operation. ${ }^{1,2}$

We have reported that RV outflow reconstruction with pedicled pericardium might be useful to reduce late stenosis after the operation. ${ }^{2}$ In this article we present a case of RV outflow tract reconstruction with nonsutured, pedicled, autologous pericardium.

From the Department of Cardiovascular Surgery, Graduate School of Medicine, Tohoku University, Sendai, Japan.

J Thorac Cardiovasc Surg 2001;121:1203-5

Copyright (C) 2001 by The American Association for Thoracic Surgery

$0022-5223 / 2001 \$ 35.00+0 \quad \mathbf{1 2 / 5 4 / 1 1 1 6 5 0}$

doi: $10.1067 / \mathrm{mtc} .2001 .111650$
Clinical summary. A 6-year-old boy with coarctation of the aorta and aortic valvular stenosis was referred for total correction. Preoperative cardiac catheterization revealed a pressure gradient of $30 \mathrm{~mm} \mathrm{Hg}$ at the level of coarctation and $90 \mathrm{~mm} \mathrm{Hg}$ between the left ventricle and ascending aorta. At first, he received coarctectomy and end-to-end anastomosis of the aorta through a left thoracotomy.

Three months after the initial operation, the Ross procedure was performed. After median sternotomy, the pericardium was trimmed because the pedicle was situated at the left cephalic side of the scheduled new extracardiac conduit. Cardiopulmonary bypass was started after cannulation into the ascending aorta, superior vena cava, and inferior vena cava. After clamping of the ascending aorta, combined antegrade and retrograde blood cardioplegic solution was infused. The aortic valve showed fibrous thickening and fusion of the right coronary and noncoronary cusps.

After the pulmonary valve had been checked, the pulmonary autograft was harvested by transection of the pulmonary artery just below the pulmonary bifurcation and 5 to $7 \mathrm{~mm}$ below the base of the pulmonary sinuses. The aortic valve was excised, and the coronary arteries were preserved on buttons. The aortic and pulmonary annular diameters were 16 and $22 \mathrm{~mm}$, respectively. The pulmonary autograft was

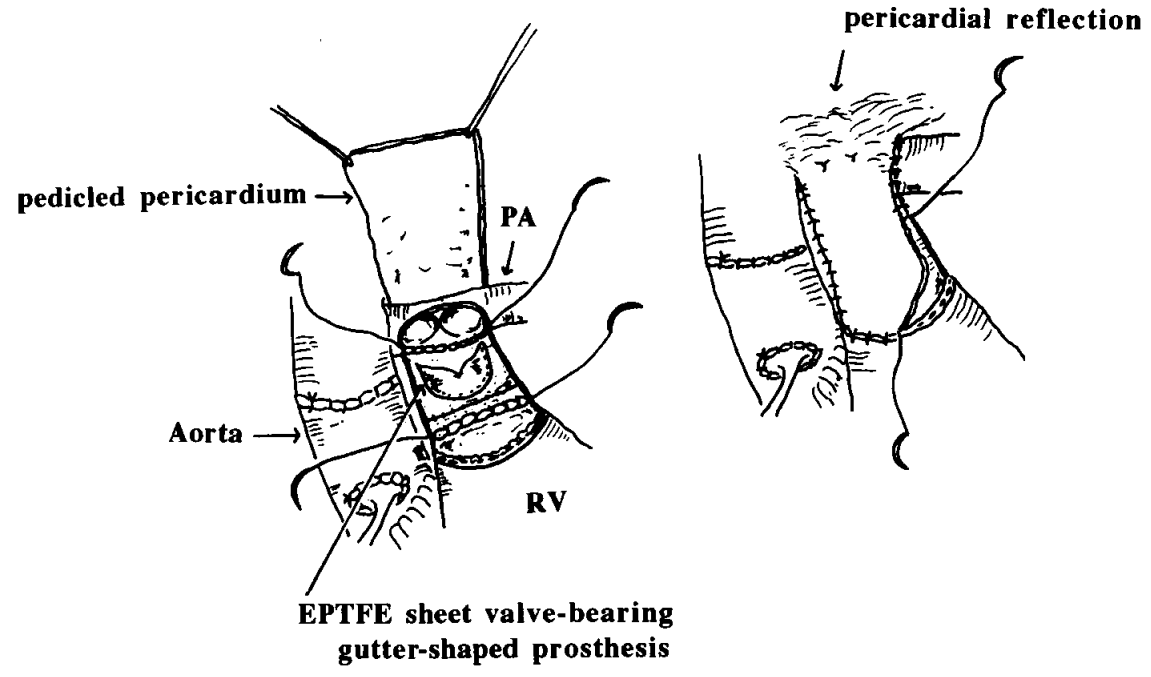

Fig 1. Operative procedure for reconstruction of the RV outflow tract. The posterior wall is constructed of the expanded polytetrafluoroethylene (EPTFE) sheet valve-bearing, gutter-shaped prosthesis (left). The anterior wall is reconstructed by using the pedicled pericardium with no suturing of the cephalad portion with pericardial reflection. $P A$, Pulmonary artery. 


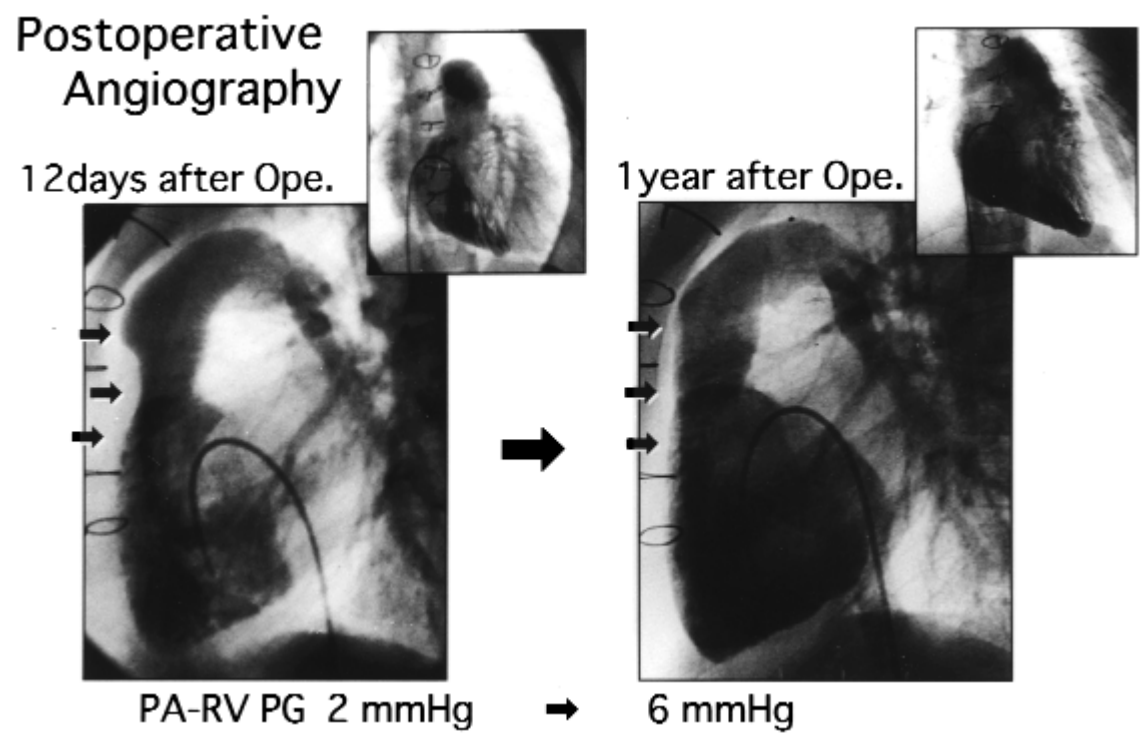

Fig 2. Postoperative pulmonary angiograms (lateral view) at 2 months (left) and 12 months (right) after operation. There is no stenosis and aneurysmal change. The pulmonary trunk at 12 months after operation (Ope) became larger than at 2 months after operation. $P A$, Pulmonary artery.

sutured to the aortic anulus with 28 interrupted 4-0 polypropylene sutures. The interupted sutures were tied over a pericardial strip to aid hemostasis. A bilateral coronary button was anastomosed to the graft with continuous 5-0 polypropylene sutures.

The proximal side of the gutter-shaped extracardiac conduit was sutured to the superior margin of the right ventriculotomy with continuous 4-0 polypropylene sutures reinforced with autologous pericardium. The distal side was sutured to the pulmonary arteriotomy with continuos 4-0 polypropylene sutures. The anterior wall of the extracardiac conduit was reconstructed with pedicled autologous pericardium (Fig 1).

The cephalad portion of the pedicled pericardium was not sutured by using pericardial reflection. The right and left lateral sides of the pericardium were sutured to the guttershaped vascular prosthesis with continuous 4-0 polypropylene sutures (Fig 1). The pericardium was tailored because the diameter of extracardiac conduit became $20 \mathrm{~mm}$. On completion of anastomosis, the aortic crossclamp was released. Weaning from cardiopulmonary bypass was smooth, and the postoperative course was uneventful. Postoperative angiography showed slight pulmonary regurgitation but no aortic regurgitation. A pulmonary angiogram 1 year after the operation showed no stenosis or tendency to enlargement (Fig 2).

Discussion. Long-term results of RV outflow reconstruction with homografts, heterografts, or valved pericardial conduits have been disappointing. Late failure is mainly associated with peel tissue ingrowth, calcification, degeneration, or shrinkage. To avoid such complication, new techniques, such as direct anastomosis between the RV and pulmonary arteries, RV outflow reconstruction with pedicled autologous pericardium, or the réparation à l'étage ventriculaire (REV) method, ${ }^{3,4}$ have been described. These methods may effectively reduce the reoperation rate but cannot be used in all cases. Although it is reported that RV reconstruction with pedicled autologous pericardium is useful to prevent late stenosis, long-term results are unclear. ${ }^{2,3}$

The major concern with these techniques is that the pedicled part of the pericardium is sutured, and it is caused by ischemic shrinkage or growth disturbance. It is reported that, experimentally, broad nonsutured pedicled pericardium grows, whereas the sutured pericardium does not. ${ }^{5}$ We compared the experimentally pedicled pericardial patch with the free pericardial patch ${ }^{2}$ and showed that the pedicled pericardium was more pliable and showed less fibrotic change than the free one, although it did not grow significantly.

An extracardiac conduit with nonsutured pedicled pericardium has the potential, but we need longer follow-up to elucidate the late results.

Received for publication Sept 5, 2000; accepted for publication Sept 19, 2000.

Address for reprints: Koichi Tabayashi, MD, Department of Cardiovascular Surgery, Graduate School of Medicine, Tohoku University, 1-1 Seiryo-cho, Aoba-ku, Sendai, Miyagi, 980-8574 Japan (E-mail: ktaba@mail.cc.tohoku.ac.jp).

\section{REFERENCES}

1. Sark J, Bull C, Stajevic M, Jothi M, Elliot M, de Leval M. Fate of subpulmonary homograft conduits: determinants of late homograft failure. J Thorac Cardiovasc Surg 1998;115:506-16.

2. Sato K, Iguchi A, Tanaka Y, Hata M, Sadahiro M, Yokoyama H, 
et al. Pedicled pericardial flap for pulmonary artery in adult dogs. Jpn J Thorac Cardiovasc Surg 2000;48:211-6.

3. Khoury W, Lang-Lazdunski L, Vernant F, Thibert M, Leca F. Pedicled pericardium for repair of right ventricular outflow tract and pulmonary arterial stenosis in tetralogy of Fallot: a six-year experience. J Thorac Cardiovasc Surg 1996;112:424-32.
4. Lecompte Y, Neveux JY, Leca F, Zannini L, Tu TV, Duboys Y, et al. Reconstruction of the pulmonary outflow tract without prosthetic conduit. J Thorac Cardiovasc Surg 1982;84:127-33.

5. Lepley D Jr, Hausmann PF, Weisel W. The fate of pericardial pedicled graft used in a fixed position in various chambers of the dog heart. J Thorac Cardiovasc Surg 1959;37:711-9. 